\title{
Association between Receipt of Intrapartum Magnesium Sulfate and Postpartum Hemorrhage
}

\author{
Emily M.S. Miller, MD, MPH ${ }^{1}$ \\ Lynn M. Yee, MD, MPH ${ }^{1}$
${ }^{1}$ Division of Maternal-Fetal Medicine, Department of Obstetrics and Gynecology, Northwestern University Feinberg School of Medicine, Chicago, Illinois
2 Department of Obstetrics and Gynecology, Northwestern University Feinberg School of Medicine, Chicago, Illinois
${ }^{3}$ Department of Anesthesiology, Northwestern University Feinberg School of Medicine, Chicago, Illinois

Am J Perinatol Rep 2021;11:e21-e25.

\author{
Elise Leger, $\mathrm{MD}^{2} \quad$ Elizabeth Lange, $\mathrm{MD}^{3}$
}

Address for correspondence Emily S. Miller, MD, MPH, 250 E. Superior St., Room 05-2175, Chicago, IL 60611 (e-mail: Emily-Miller-1@northwestern.edu).

\begin{abstract}
Keywords

- hypertensive disorders of pregnancy

- magnesium sulfate

- obstetrics

- postpartum hemorrhage

Objective The aim of the study is to investigate the association between intrapartum administration of magnesium sulfate in women with hypertensive disorders of pregnancy and postpartum hemorrhage.

Study Design This was a retrospective cohort study of women diagnosed with a hypertensive disorder of pregnancy who delivered singleton gestations $>32$ weeks at a single, large volume tertiary care center between January 2006 and February 2015. Women who received intrapartum magnesium sulfate for seizure prophylaxis were compared with women who did not receive intrapartum magnesium sulfate. The primary outcome was frequency of postpartum hemorrhage. Secondary outcomes included estimated blood loss, uterine atony, and transfusion of packed red blood cells. Bivariable analyses were used to compare the frequencies of each outcome. Multivariable logistic regression models examined the independent associations of magnesium sulfate with outcomes.

Results Of 2,970 women who met inclusion criteria, 1,072 (36\%) received intrapartum magnesium sulfate. Women who received magnesium sulfate were more likely to be nulliparous, publicly insured, of minority race or ethnicity, earlier gestational age at delivery, and undergo labor induction. The frequency of postpartum hemorrhage was significantly higher among women who received magnesium sulfate compared with those who did not ( 12.4 vs. $9.3 \%, p=0.008$ ), which persisted after controlling for potential confounders. Of secondary outcomes, there was no difference in estimated blood loss between women who did and did not receive magnesium sulfate $(250 \mathrm{~mL}$ [interquartile range 250-750] vs. $250 \mathrm{~mL}$ [interquartile range 250-750], $p=0.446$ ). However, compared with women who did not receive magnesium sulfate, women who received magnesium sulfate had a greater frequency of uterine atony ( 8.9 vs $4.9 \%$, $p<0.001)$ and transfusion of packed red blood cells ( 2.0 vs. $0.8 \%, p=0.008)$. These differences persisted after controlling for potential confounders.
\end{abstract}

received

June 4,2020

accepted after revision

September 24, 2020
DOI https://doi.org/

10.1055/s-0040-1721671. ISSN 2157-6998. (c) 2021. The Author(s).

This is an open access article published by Thieme under the terms of the Creative Commons Attribution-NonDerivative-NonCommercial-License, permitting copying and reproduction so long as the original work is given appropriate credit. Contents may not be used for commercial purposes, or adapted, remixed, transformed or built upon. (https://creativecommons.org/ licenses/by-nc-nd/4.0/)

Thieme Medical Publishers, Inc., 333 Seventh Avenue, 18th Floor, New York, NY 10001, USA 
Conclusion Intrapartum magnesium sulfate administration to women with hypertensive disorders of pregnancy is associated with increased odds of postpartum hemorrhage, uterine atony, and red blood cell transfusion.

Preeclampsia is a leading cause of maternal morbidity and mortality worldwide, and its incidence has increased by $25 \%$ in the United States over the past two decades. ${ }^{1-5}$ Magnesium sulfate is commonly administered during the intrapartum and early postpartum periods for seizure prophylaxis in women with preeclampsia. ${ }^{6,7}$ The American College of Obstetricians and Gynecologists specifically recommends the administration of magnesium sulfate in labor and continuing for 24 hours postpartum in women meeting criteria for preeclampsia with severe features. ${ }^{8}$ However, for women with a hypertensive disorder of pregnancy without severe features, there remains clinical equipoise about the utility of magnesium sulfate for seizure prophylaxis. ${ }^{8}$

Despite decades of study, the mechanism of action of magnesium sulfate is poorly understood. However, one side effect of magnesium sulfate is uterine relaxation mediated by competition with calcium and inhibiting myosin light-chain kinase activity. ${ }^{9,10}$ Although this theoretical uterine relaxation has not proven to arrest preterm labor ${ }^{11}$ and thus its use as a tocolytic is not recommended; concern exists that intrapartum use of magnesium sulfate could increase the risk of postpartum hemorrhage ( $\mathrm{PPH}$ ) by preventing the uterus from contracting appropriately after delivery.

Existing literature on this relationship is conflicting, with some data suggesting an increased risk of bleeding ${ }^{12-14}$ and other data not confirming a significant difference in blood loss at delivery. ${ }^{15}$ These data are limited by inadequate power and lack of control for significant confounders. As PPH remains a leading cause of maternal morbidity and mortality, understanding risk factors for hemorrhage is essential to prevent adverse maternal outcomes. ${ }^{5,16-19}$ Further, elucidating the potential relationship between magnesium and hemorrhage may shed light on areas to guide hemorrhage preparedness. Thus, the objective of this study is to determine if intrapartum magnesium exposure in women with a hypertensive disorder of pregnancy is associated with PPH.

\section{Methods}

This is a retrospective cohort study of women diagnosed with a hypertensive disorder of pregnancy who delivered at a single large academic medical center between January 2006 and February 2015. Women were eligible for inclusion if they delivered after 32 weeks of gestation, were 18 years of age or greater, had a singleton gestation, and were diagnosed by their obstetrician or midwife with a hypertensive disorder of pregnancy. All hypertensive disorders of pregnancy (gestational hypertension, preeclampsia, eclampsia, or HELLP syndrome) were eligible for inclusion regardless of presence of severe features. Women who delivered $<32$ weeks were excluded due to the use of magnesium sulfate for fetal neuroprotection during some years of the study period.
Women with an intrauterine fetal demise, contraindications to magnesium sulfate, and without documentation of estimated blood loss (EBL) were excluded. Women whose administration of magnesium sulfate began postpartum were also excluded. Eligible records were identified via query of the electronic medical record used for clinical care.

During the study period, general practice at this institution included administration of magnesium sulfate for seizure prophylaxis to all women with preeclampsia with severe features or HELLP syndrome. Administration of magnesium sulfate in the setting of other hypertensive disorders of pregnancy was at the discretion of the obstetrician or midwife. For women who did receive magnesium sulfate, a loading dose of $4 \mathrm{~g}$ was administered over 20 minutes followed by a maintenance rate of $2 \mathrm{~g} / \mathrm{h}$. The maintenance rate was adjusted for women with evidence of renal disease or injury.

Demographic and baseline clinical data were abstracted, including maternal age, self-reported race/ethnicity, insurance status, tobacco use, and maternal medical comorbidities (chronic hypertension, pregestational diabetes). Obstetric data abstracted included parity, abnormal placentation (e.g., abruption or placenta previa), induction of labor, gestational age at delivery, delivery analgesia, chorioamnionitis, mode of delivery, and neonatal birth weight. Hemorrhage-related data collected included total EBL, etiology of the PPH (if present), and a detail of whether a transfusion of packed red blood cells (PRBCs) was administered or not.

At this institution, the volume of blood loss is routinely estimated by the delivering provider or obstetric anesthesiologist. EBL may be determined either by clinical or volumetric assessment based on the clinical scenario. All providers underwent training in the assessment and management of PPH as has been previously described. ${ }^{20}$ During the study period, the electronic medical record delivery form allowed for either numeric entry of EBL or selection of several ranges (e.g., $<500 \mathrm{~mL}$ or $500-1,000 \mathrm{~mL}$ ). For women whose EBL was recorded as a range, the mean of that range was used for analyses. PPH was defined as delivery EBL of at least $500 \mathrm{~mL}$ for a vaginal delivery and at least $1,000 \mathrm{~mL}$ for a cesarean delivery, consistent with the extant definition at the time of the study. ${ }^{21}$ The etiology of the PPH was based on clinical judgment and routinely described by the obstetrician or midwife in the delivery documentation. Etiology of the $\mathrm{PPH}$ was classified as uterine atony versus all other etiologies.

The primary outcome was frequency of PPH. Secondary outcomes included EBL, frequency of uterine atony as etiology of hemorrhage, and frequency of packed red blood cell transfusion. Bivariable analyses were used to compare the frequency of these outcomes between women who did and 
did not receive intrapartum magnesium sulfate for seizure prophylaxis. Chi-square tests were used for categorical variables. Student's $t$-tests or Mann Whitney U tests were used for continuous variables, as appropriate. Multivariable logistic regression analyses were utilized to examine the independent relationships between magnesium sulfate administration and hemorrhage outcomes after controlling for potential confounders ( $p<0.05$ on bivariable analyses). Analyses were performed using Stata version 14.0 (StataCorp, College Station, TX). The Northwestern University Institutional Review Board approved this study with a waiver of consent prior to its initiation.

\section{Results}

Of the 2,970 women who met inclusion criteria during the study period, $36 \%(N=1,072)$ received intrapartum magnesium sulfate. Women who received magnesium sulfate were younger and more likely to be nulliparous, publicly insured, and were less likely to be non-Hispanic white (-Table $\mathbf{1}$ ). They also delivered at an earlier gestational age, and, correspondingly, had lower birthweight infants. There were no differences in the diagnosis of pregestational diabetes, abnormal placentation, or cesarean delivery between the cohorts. However, women who received magnesium sulfate were significantly more likely to have undergone induction of labor compared with women who did not receive magnesium sulfate.

Three-hundred and ten (10.4\%) women experienced PPH. The frequency of PPH was significantly higher in women who received magnesium sulfate compared with those who did not (12.4 vs. $9.3 \%, p=0.008)$. After controlling for potential confounders, the odds of PPH remained greater for women who received magnesium sulfate (adjusted odds ratio 1.72 , 95\% CI 1.32-2.24; - Table 2).

There was no difference in EBL between women who did and did not receive magnesium sulfate $(250 \mathrm{~mL}$ [250-750] vs. $250 \mathrm{~mL}$ [250-750], $p=0.446$ ). However, compared with women who did not receive magnesium sulfate, women who received magnesium sulfate had a higher incidence of uterine atony ( 8.9 vs. $4.9 \%, p<0.001$ ) and transfusion of PRBCs ( 2.0 vs. $0.8 \%, p=0.008$ ). These differences persisted after controlling for potential confounders (-Table $\mathbf{2}$ ).

\section{Discussion}

It has been theorized that use of magnesium sulfate during labor may increase the risk of PPH due to enhanced uterine relaxation. In this study of a large, diverse cohort of women with hypertensive disorders of pregnancy, intrapartum magnesium sulfate administration was associated with greater odds of PPH, uterine atony, and red blood cell transfusion. These findings persisted after controlling for confounding factors. The potential biological mechanisms for these findings are multifold. First, magnesium acts as a calcium antagonist, and decreased intracellular calcium can lead to inactivation of calmodulin-dependent myosin light chain kinase activity and decreased muscle contraction, thus lead- ing to enhanced uterine relaxation. ${ }^{22}$ Further, magnesium has been found to inhibit myometrial contractility and uterine contractions ${ }^{23}$ and also acts as a potent vasodilator of human uterine arteries, especially those of pregnant women. ${ }^{24}$ These mechanisms could lead to an increased risk of PPH.

Limited data have examined this relationship between magnesium sulfate administration and hemorrhage risk, despite this theoretical relationship. Our findings contrast with a systematic review by Heman and Van Der Linden that did not find a statistically significant increase in PPH after use of magnesium sulfate. ${ }^{25}$ However, two of the four included studies $^{7,26}$ used lower doses of magnesium sulfate than is considered standard clinical practice, potentially biasing their results toward the null. A meta-analysis of several randomized trials by Graham et al found that blood loss at the time of delivery was not affected by magnesium sulfate given for eclampsia prophylaxis, but this study did not include separate data for cesarean and vaginal deliveries. ${ }^{27}$ Two studies have identified a positive relationship between intrapartum magnesium administration and blood loss at delivery. Belfort et al identified a 2.5-fold increased risk of PPH in women who received magnesium sulfate versus placebo. ${ }^{28}$ Friedman et al did not directly assess $\mathrm{PPH}$, however, they identified a greater EBL (606 vs. $418 \mathrm{~mL}, p=0.04$ ) and a larger reduction in hematocrit ( 7.6 vs. $4.7 \%, p=0.003$ ) in women who received magnesium sulfate versus phenytoin for seizure prophylaxis. ${ }^{13}$

Although magnesium sulfate is recommended for seizure prophylaxis among women with preeclampsia with severe features and/or HELLP, in all other patients, its use must be carefully considered in light of these findings. Hemorrhage remains a major source of maternal morbidity and mortality, and understanding risk factors for $\mathrm{PPH}$, such as intrapartum magnesium sulfate administration, is essential to reducing hemorrhage-associated maternal morbidities and mortality. The clinical equipoise on use of magnesium sulfate for women with preeclampsia without severe features suggests obstetricians must weigh the risks versus benefits of magnesium in this population. Given the low number needed to treat for women with preeclampsia without severe features or with gestational hypertension, these findings suggest the potential for harm due to PPH must be carefully balanced with the potential benefit of seizure prophylaxis. ${ }^{7}$

There are several limitations to our study. This study was conducted at a single tertiary care institution and thus results may not be fully generalizable. Specifically, the homogeneity of practice patterns within our institution with respect to magnesium sulfate dosing and the lack of systematic obtainment of magnesium serum levels preclude analysis of any dose-response relationship. Additionally, our data only include magnesium sulfate exposure in women with a hypertensive disorder of pregnancy; women who received magnesium prior to 32 weeks for fetal neuroprotection were excluded. Future research is necessary to determine if women who receive magnesium sulfate for fetal neuroprotection also experience increased odds of $\mathrm{PPH}$. Finally, due to collinearity with receipt of magnesium sulfate, we were unable to control for severity of the underlying 
Table 1 Patient characteristics stratified by receipt of intrapartum magnesium sulfate

\begin{tabular}{|c|c|c|c|}
\hline & $\begin{array}{l}\text { Did not receive } \\
\text { magnesium sulfate } \\
n=1898\end{array}$ & $\begin{array}{l}\text { Received } \\
\text { magnesium sulfate } \\
n=1072\end{array}$ & $p$-Value \\
\hline Age (year) & $31.4 \pm 5.8$ & $30.8 \pm 6.1$ & 0.005 \\
\hline \multicolumn{4}{|l|}{ Race/ethnicity } \\
\hline Non-Hispanic white & 979 (51.6\%) & $466(43.5 \%)$ & \multirow[t]{5}{*}{$<0.001$} \\
\hline Non-Hispanic black & $333(17.5 \%)$ & $192(17.9 \%)$ & \\
\hline Hispanic & $233(12.3 \%)$ & $186(17.4 \%)$ & \\
\hline Asian & $61(3.2 \%)$ & $44(4.1 \%)$ & \\
\hline Other/Unknown & $292(15.4 \%)$ & $184(17.2 \%)$ & \\
\hline Public insurance & $391(20.6 \%)$ & $312(29.1 \%)$ & $<0.001$ \\
\hline History of tobacco use & $328(17.3 \%)$ & $199(18.6 \%)$ & 0.380 \\
\hline Chronic hypertension & $346(18.2 \%)$ & $138(12.9 \%)$ & $<0.001$ \\
\hline Pregestational diabetes & $136(7.2 \%)$ & $83(7.7 \%)$ & 0.563 \\
\hline Nulliparous & $1,367(72.0 \%)$ & $843(78.6 \%)$ & $<0.001$ \\
\hline More than four prior births & $20(1.1 \%)$ & $5(0.5 \%)$ & 0.092 \\
\hline Abnormal placentation (previa or abruption) & $39(2.1 \%)$ & $18(1.7 \%)$ & 0.474 \\
\hline Induction of labor (vs. spontaneous) & $1,050(60.8 \%)$ & $768(73.8 \%)$ & $<0.001$ \\
\hline Gestational age at delivery (weeks) & $39.0(38.0-40.0)$ & $38.1(36.7-39.4)$ & $<0.001$ \\
\hline Preterm delivery & $167(8.8 \%)$ & $308(28.7 \%)$ & $<0.001$ \\
\hline \multicolumn{4}{|l|}{ Anesthesia } \\
\hline None & 107 (5.6\%) & $56(5.2 \%)$ & \multirow[t]{4}{*}{0.557} \\
\hline Spinal/epidural & $1,741(91.7 \%)$ & $992(92.5 \%)$ & \\
\hline Intravenous narcotics & $12(0.6 \%)$ & $9(0.8 \%)$ & \\
\hline General anesthesia & $38(2.0 \%)$ & $15(1.4 \%)$ & \\
\hline Chorioamnionitis & $169(8.9 \%)$ & $44(4.1 \%)$ & $<0.001$ \\
\hline Cesarean delivery & $702(37.0 \%)$ & $364(34.0 \%)$ & 0.098 \\
\hline Birth weight $(\mathrm{kg})$ & $3.27 \pm 0.55$ & $2.95 \pm 0.60$ & $<0.001$ \\
\hline Macrosomia $(>4.0 \mathrm{~kg})$ & $162(8.5 \%)$ & $46(4.3 \%)$ & $<0.001$ \\
\hline
\end{tabular}

Note: Data presented as mean \pm standard deviation, $n(\%)$, or median (interquartile range).

disease state. Thus, this observed relationship could be attributed to the severity of the hypertensive disorder itself and not magnesium sulfate. In addition, this cohort included women that delivered prior to the release of the ACOG Task Force Report on Hypertension in Pregnancy in 2013, which further clarified which patients should receive magnesium prophylaxis. ${ }^{8}$ Given this, the severity of underlying disease in this cohort cannot be accurately classified and it remains a potential confounder.

Future research should focus on confirming this observed association between intrapartum magnesium sulfate administration and $\mathrm{PPH}$ in other settings along with analyzing a potential dose-response relationship. If confirmed, clinicians must weigh carefully the possibility of increased risk

Table 2 Association of magnesium receipt with the outcome of postpartum hemorrhage, uterine atony, and transfusion of packed red blood cells

\begin{tabular}{|l|l|l|l|l|}
\hline & Odds ratio & $95 \% \mathrm{Cl}$ & Adjusted odds ratio $^{\text {a }}$ & 95\% $\mathrm{Cl}$ \\
\hline Postpartum hemorrhage & 1.40 & $1.11-1.77$ & 1.72 & $1.32-2.24$ \\
\hline Uterine atony & 1.81 & $1.34-2.45$ & 2.39 & $1.73-3.32$ \\
\hline Transfusion of PRBCs & 3.43 & $1.65-7.11$ & 3.00 & $1.42-6.35$ \\
\hline
\end{tabular}

Abbreviations: $\mathrm{Cl}$, confidence interval; PRBC, packed red blood cells.

${ }^{a}$ After adjusting for age, nulliparity, race/ethnicity, public insurance, chronic hypertension, preterm delivery, induction of labor, chorioamnionitis, and birth weight. 
of PPH versus the established benefits of magnesium sulfate in seizure prophylaxis when making individual treatment decisions in the setting of hypertensive disorders of pregnancy. Furthermore, this information could be used to guide hemorrhage preparedness when caring for patients requiring intrapartum magnesium sulfate.

\section{Condensation}

Intrapartum magnesium sulfate administration to women with hypertensive disorders of pregnancy is associated with increased odds of postpartum hemorrhage.

\section{Presentation}

This abstract was presented as a poster at the Society for Maternal-Fetal Medicine 38th Annual Meeting in Dallas, Texas (January 29 to February 3, 2018).

Funding

E.S.M. and L.M.Y. were supported by the NICHD K12 HD050121-09 and K12 HD050121-11, respectively, at the time of the investigation. Research reported in this publication was supported, in part, by the National Institutes of Health's National Center for Advancing Translational Sciences, Grant Number UL1TR001422. The content is solely the responsibility of the authors and does not necessarily represent the official views of the National Institutes of Health.

\section{Conflict of Interest}

The authors report no conflict of interest.

\section{References}

1 Wallis AB, Saftlas AF, Hsia J, Atrash HK. Secular trends in the rates of preeclampsia, eclampsia, and gestational hypertension, United States, 1987-2004. Am J Hypertens 2008;21(05):521-526

2 Högberg U. The World Health Report 2005: "make every mother and child count"-including Africans. Scand J Public Health 2005; 33(06):409-411

3 Duley L. Maternal mortality associated with hypertensive disorders of pregnancy in Africa, Asia, Latin America and the Caribbean. Br J Obstet Gynaecol 1992;99(07):547-553

4 Ghulmiyyah L, Sibai B. Maternal mortality from preeclampsia/eclampsia. Semin Perinatol 2012;36(01):56-59

5 Creanga AA, Berg CJ, Syverson C, Seed K, Bruce FC, Callaghan WM. Pregnancy-related mortality in the United States, 2006-2010. Obstet Gynecol 2015;125(01):5-12

6 American College of Obstetricians and Gynecologists. Magnesium sulfate use in obstetrics, Committee Opinion No. 652. Obstet Gynecol 2016;127:e52-e53

7 Altman D, Carroli G, Duley L, et al;Magpie Trial Collaboration Group. Do women with pre-eclampsia, and their babies, benefit from magnesium sulphate? The Magpie Trial: a randomised placebo-controlled trial. Lancet 2002;359(9321):1877-1890

8 American College of Obstetricians and Gynecologists Task Force on Hypertension in Pregnancy. Hypertension in pregnancy. Report of the American College of Obstetricians and Gynecologists' Task Force on Hypertension in Pregnancy. Obstet Gynecol 2013; 122(05):1122-1131

9 Mizuki J, Tasaka K, Masumoto N, Kasahara K, Miyake A, Tanizawa O. Magnesium sulfate inhibits oxytocin-induced calcium mobilization in human puerperal myometrial cells: possible involve- ment of intracellular free magnesium concentration. Am J Obstet Gynecol 1993;169(01):134-139

10 Lemancewicz A, Laudańska H, Laudański T, Karpiuk A, Batra S. Permeability of fetal membranes to calcium and magnesium: possible role in preterm labour. Hum Reprod 2000;15(09):2018-2022

11 Crowther CA, Brown J, McKinlay CJ, Middleton P. Magnesium sulphate for preventing preterm birth in threatened preterm labour. Cochrane Database Syst Rev 2014;(08):CD001060

12 Fuentes A, Rojas A, Porter KB, Saviello G, O'Brien WF. The effect of magnesium sulfate on bleeding time in pregnancy. Am J Obstet Gynecol 1995;173(04):1246-1249

13 Friedman SA, Lim KH, Baker CA, Repke JT. Phenytoin versus magnesium sulfate in preeclampsia: a pilot study. Am J Perinatol 1993;10(03):233-238

14 Grotegut CA, Paglia MJ, Johnson LN, Thames B, James AH. Oxytocin exposure during labor among women with postpartum hemorrhage secondary to uterine atony. Am J Obstet Gynecol 2011;204(01):56.e1-56.e6

15 Witlin AG, Friedman SA, Sibai BM. The effect of magnesium sulfate therapy on the duration of labor in women with mild preeclampsia at term: a randomized, double-blind, placebo-controlled trial. Am J Obstet Gynecol 1997;176(03):623-627

16 Committee on Practice Bulletins-Obstetrics. Practice Bulletin No. 183: postpartum hemorrhage. Obstet Gynecol 2017;130(04): e168-e186

17 Callaghan WM, Kuklina EV, Berg CJ. Trends in postpartum hemorrhage: United States, 1994-2006. Am J Obstet Gynecol 2010;202 (04):353.e1-353.e6

18 World Health Organization WHO Recommendations for the Prevention and Treatment of Postpartum Hemorrhage. Geneva: World Health Organization; 2012

19 Creanga AA, Syverson C, Seed K, Callaghan WM. Pregnancyrelated mortality in the United States, 2011-2013. Obstet Gynecol 2017;130(02):366-373

20 Einerson BD, Miller ES, Grobman WA. Does a postpartum hemorrhage patient safety program result in sustained changes in management and outcomes? Am J Obstet Gynecol 2015;212 (02):140-4.e1

21 American College of Obstetricians and Gynecologists. Practice Bulletin No. 76: postpartum hemorrhage. Obstet Gynecol 2006; 108:1039-1047

22 Altura BM, Altura BT, Carella A, Gebrewold A, Murakawa T, Nishio A. Mg2+-Ca2+ interaction in contractility of vascular smooth muscle: Mg2 + versus organic calcium channel blockers on myogenic tone and agonist-induced responsiveness of blood vessels. Can J Physiol Pharmacol 1987;65(04):729-745

23 Fomin VP, Gibbs SG, Vanam R, Morimiya A, Hurd WW. Effect of magnesium sulfate on contractile force and intracellular calcium concentration in pregnant human myometrium. Am J Obstet Gynecol 2006;194(05):1384-1390

24 Nelson SH, Suresh MS. Magnesium sulfate-induced relaxation of uterine arteries from pregnant and nonpregnant patients. Am J Obstet Gynecol 1991;164(5 Pt 1):1344-1350

25 Heman L, Van Der Linden P. Does magnesium sulfate increase the incidence of postpartum hemorrhage? Open J Obstet Gynecol 2011;1:168-173

26 Crowther CA, Hiller JE, Doyle LW, Haslam RR. Australasian Collaborative Trial of Magnesium Sulphate (ACTOMg SO4) Collaborative Group. Effect of magnesium sulfate given for neuroprotection before preterm birth: a randomized controlled trial. JAMA 2003; 290(20):2669-2676

27 Graham NM, Gimovsky AC, Roman A, Berghella V. Blood loss at cesarean delivery in women on magnesium sulfate for preeclampsia. J Matern Fetal Neonatal Med 2016;29(11):1817-1821

28 Belfort MA, Anthony J, Saade GR, Allen JC Jr. Nimodipine Study Group. A comparison of magnesium sulfate and nimodipine for the prevention of eclampsia. N Engl J Med 2003;348(04):304-311 